\title{
Inhibition of HIV early replication by the p53 and its downstream gene p21
}

\author{
Binshan Shi ${ }^{1 *}$ D, Hamayun J. Sharifi ${ }^{1}$, Sara DiGrigoli ${ }^{1}$, Michaela Kinnetz', Katie Mellon', Wenwei ${ }^{1}{ }^{2}$
} and Carlos M. C. de Noronha ${ }^{3}$

\begin{abstract}
Background: The tumor suppressor gene p53 has been found to suppress HIV infection by various mechanisms, but the inhibition of HIV at an early stage of replication by host cell p53 and its downstream gene p21 has not been well studied.

Method: VSV-G pseudotyped HIV-1 or HIV-2 viruses with GFP or luciferase reporter gene were used to infect HCT116 p53 $3^{+/+}$cells, HCT116 p53 $3^{-/-}$cells and hMDMs. The infections were detected by flow cytometry or measured by luciferase assay. Reverse transcription products were quantified by a TaqMan real time PCR. siRNA knockdown experiments were applied to study potential roles of p53 and p21 genes in their restriction to HIV infection. Western blot experiments were used to analyze changes in gene expression.

Results: The infection of HIV-1 was inhibited in HCT116 p53 $3^{+/+}$cells in comparison to HCT116 p53 $3^{-/-}$cells. The fold of inhibition was largely increased when cell cycle switched from cycling to non-cycling status. Further analysis showed that both p53 and p21 expressions were upregulated in non-cycling HCT116 p53 ${ }^{+/+}$cells and HIV-1 reverse transcription was subsequently inhibited. siRNA knockdown of either p53 or p21 rescued HIV-1 reverse transcription from the inhibition in non-cycling HCT116 $\mathrm{p} 53^{+/+}$cells. It was identified that the observed restrictions by p53 and p21 were associated with the suppression of RNR2 expression and phosphorylation of SAMHD1. These observations were confirmed by using siRNA knockdown experiments. In addition, p53 also inhibited HIV-2 infection in HCT116 p53 $3^{+/+}$cells and siRNA knockdown of p21 increased HIV-2 infection in hMDMs. Finally the expressions of p53 and p21 were found to be induced in hMDMs shortly after HIV-1 infection.
\end{abstract}

Conclusions: The p53 and its downstream gene p21 interfere with HIV early stage of replication in non-cycling cells and hMDMs.

Keywords: p53, p21, HIV-1, HIV-2, Reverse transcription, Cell cycle, SAMHD1, RNR2

\section{Background}

The tumor suppressor gene p53 has been suggested to play an important role in the restriction of the human immunodeficiency virus type 1 (HIV-1) infection for decades. p53 is activated in human immune cells after HIV-1 infection [1-3], and p53 expression is induced by type I interferons (IFN- $\alpha / \beta)$ after viral infection $[2,4]$. A variety of mechanisms have been proposed to reveal p53 mediated restrictions to HIV infection. Early studies found that p53 inhibited HIV-1 long terminal repeat

\footnotetext{
* Correspondence: Binshan.shi@acphs.edu

'Department of Basic and Clinical Sciences, Albany College of Pharmacy and

Health Sciences, 106 New Scotland Ave, Albany, NY 12208, USA

Full list of author information is available at the end of the article
}

(LTR) promoter activity and repressed transcription from the HIV-1 proviral genome [5-7]. p53 was also found to suppress Tat, a major transactivator of HIV-1 [8]. More recently Yoon et al. reported that p53 induced the expression of PKR, and then PKR inactivated HIV-1 Tat by phosphorylation. Many other works reported that HIV-1 infection caused immune cell's death by inducing p53 dependent apoptosis [1, 9-12]. Additionally, it was postulated that p53 might impact HIV-1 reverse transcriptase function $[13,14]$, but detailed mechanism remains to be determined at the cellular level. The evidence that p53 inhibits HIV-1 at an early stage of replication has not been reported previously. 
One of the p53 downstream genes, the cyclin-dependent kinase inhibitor $\mathrm{p} 21^{\mathrm{Waf1} / \mathrm{Cip} 1}$ (referred to hereafter as $\mathrm{p} 21$ ) has been documented for its role in antiretroviral infection [15-21]. The expression of p21 in human macrophages was induced after HIV-1 infection [19]. Upregulation of p21 was also found in $\mathrm{CD}_{4}^{+} \mathrm{T}$ cells from elite controllers, a unique group of HIV-1-infected individuals with undetectable HIV-1 replication in the absence of antiretroviral therapy $[18,22]$. siRNA knockdown of p21 resulted in increased HIV-1 infection [22]. Both Allouch et al and Pauls et al showed that p21 inhibited HIV-1 reverse transcription in macrophages through regulating level of cellular dNTPs $[17,20]$. Other data indicated that inhibition of HIV-1 reverse transcription by p21 might not be directly related with regulating the level of cellular dNTPs. Leng et al. showed that p21 inhibited CDK2-dependent phosphorylation of HIV-1 reverse transcriptase, which reduced the efficacy of HIV-1 reverse transcription [18]. Zhang et al showed that p21 prevented viral DNA integration [23]. Others reported that the restriction to HIV-1 infection by p21 was associated with viral protein $\operatorname{Vpr}[24,25]$. It was also found that p21 inhibited HIV-2 and SIV infection [16].

It was found previously by our group that p53 inhibited reverse transcription of MLV vector based retrovirus in non-cycling cells through its downstream gene p21 [26]. It was investigated in this study whether the p53 dependent host restriction to retrovirus also applies to HIV infection by using human colorectal cancer HCT116 p53 $3^{+/+}$and HCT116 $\mathrm{p} 53^{-/-}$cell lines and primary human monocyte derived macrophages (hMDMs). Interestingly, p53 and its downstream gene p21 were found upregulated in hMDMs shortly after HIV-1 infection. Our results strongly suggest their antiretroviral roles at an early stage of HIV replication.

\section{Methods}

\section{Cell culture and cell viability}

Human colorectal cancer HCT116 p53 $3^{+/+}$and HCT116 $\mathrm{p} 53^{-/-}$cell lines were generous gifts from Dr. B. Vogelstein. HEK-293 cells and TZM-bl cells were obtained from NIH AIDS Reagent Program (Germantown, MD, USA). HCT116 p53 ${ }^{+/+}$, HCT116 p53 ${ }^{-/-}$, HEK-293 and TZM-bl were propagated in Dulbecco's modified Eagle's medium (DMEM) (Life Technologies, Grand Island, NY, USA) supplemented with $10 \%$ fetal bovine serum (FBS), $2 \mathrm{mM}$ L-Glutamine, 100 units $/ \mathrm{ml}$ of penicillin and $100 \mu \mathrm{g} / \mathrm{ml}$ of streptomycin at $37{ }^{\circ} \mathrm{C}$ with $5 \% \mathrm{CO}_{2}$. A Countess II Automated Cell Counter (Thermos Fisher Scientific, Waltham, MA, USA) was used to count the number of cells in experiments as designed. Elutriated human monocytes were obtained from the University of Nebraska Medical Center. Donors were de-identified with consent procedures based on the anonymity. IRB approval has been obtained from the Committee on Research at Albany College of Pharmacy and Health Science. Monocytes were differentiated into macrophages (hMDMs) for 10-14 days in DMEM supplemented with $10 \%$ human AB serum (VWR, Radnor, PA, USA) by following procedures described previously [27]. Non-cycling

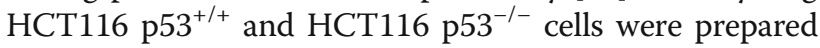
by $24 \mathrm{~h}$ serum starvation. Both cycling and non-cycling cells were tested for cell viability by using trypan blue exclusion assay, and cell death was also measured by WST-1 assay (Roche, Indianapolis, IN, USA). The percentage of live cells was counted by the Countess II Automated Cell Counter (Thermos Fisher Scientific, Waltham, MA, USA) after cells were stained by the Trypan Blue solution (Thermos Fisher Scientific, Waltham, MA, USA). WST-1 assay (Roche) was performed by following kit instruction and O.D. was measured by Eppendorf Plate Reader AF2200 (Eppendorf, Hamburg Germany).

\section{Virus preparation and cell infection}

HIV VSV-G-pseudotyped viruses were produced by transient cotransfection of HEK293 cells with proviral HIV-1 or HIV-2 plasmids together with a vesicular stomatitis virus $G$ protein (VSV-G) expression vector pVSV-G (Clontech Laboratories, Inc., Mountain View, CA, USA) by using X-tremeGENE 9 DNA Transfection Reagent (Roche, Indianapolis, IN, USA). HIV-1 plasmids pNL4-3 env(-)nef(-)gfp(+) was a gift from Dr. Vicente Planelles, pNL4-3 env(-)nef(-)luc(+) was a gift from Dr. Nathaniel Landau and HIV-2 luc(+) was a gift from Dr. Lee Ratner. Supernatants containing pseudotyped viruses were harvested $48 \mathrm{~h}$ after transfection, passed through 0.45 -nm-pore-size filters, and stored at $-80^{\circ} \mathrm{C}$. Viral titers were determined by serial dilution on the TZM-bl indicator cell line as previously described [28]. $1 \times 10^{5}$ cells/well were seeded in a 24 well plate for infection of HCT116 $\mathrm{p} 3^{+/+}$and HCT116 $\mathrm{p} 53^{-/-}$cells. For non-cycling cells, the complete medium was replaced with DMEM medium without FBS after $24 \mathrm{~h}$, and cells were infected after another $24 \mathrm{~h}$. For cycling cells the medium was replaced with fresh complete medium after $24 \mathrm{~h}$. At time of the infection, cell numbers of paired HCT116 $\mathrm{p}^{+/+}$and

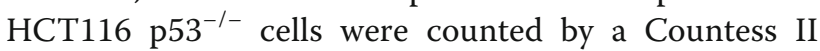
Automated Cell Counter (Thermos Fisher Scientific, Waltham, MA, USA), the same MOI was used for infection in both cells. $0.5 \times 10^{6} \mathrm{hMDMs}$ cultured in 24 well plates were used for HIV infection and siRNA experiments. Azidothymidine (AZT) and Efavirenz (EFA) were obtained from NIH AIDS Reagent Program (Germantown, MD, USA) and were dissolved in dimethyl sulfoxide (DMSO) (Sigma-Aldrich, St. Louis, MO, USA). $50 \mu \mathrm{g} / \mathrm{ml}$ AZT or EFA was used in infection experiments as controls. Inactivated virus control was made by heating virus at $65^{\circ} \mathrm{C}$ for $1 \mathrm{~h}$. 


\section{Luciferase assay}

Luciferase Assay System (Promega, Madison, WI, USA) was used and luciferase assay was performed according to the manufacturer's instructions. Cells infected with HIV-1 $\mathrm{Luc}^{+}$virus were washed with PBS, and then lysed with lysis buffer. After centrifugation at 15,000×g for $1 \mathrm{~min}, 20 \mu \mathrm{l}$ of sample supernatant was mixed with $100 \mu \mathrm{l}$ of Luciferase Assay Reagent. Luciferase activity was measured in Relative Light Units (RLU) by using a GloMax ${ }^{\oplus}$-Multi Jr Single Tube Multimode Reader (Promega, Madison, WI, USA).

\section{Flow cytometry}

Flow cytometry was used for both cell cycle analysis and quantification of infection. For cell cycle analysis by propidium iodide staining, cells were washed with PBS, fixed with ice-cold $70 \%$ ethanol, and stained with $0.1 \%(v / v)$ Triton X-100, $20 \mu \mathrm{g} / \mathrm{ml}$ propidium iodide (PI) (Sigma, St. Louis, MO, USA) and $100 \mu \mathrm{g} / \mathrm{ml}$ DNase-free RNase (Life Technologies, Grand Island, NY, USA). The Click-iT ${ }^{\mathrm{max}}$ Plus EdU Flow Cytometry Assay Kit (Life Technologies, Grand Island, NY, USA) was also used to quantify S phase cells and the kit instruction was followed. For the infection assay, cells were disassociated by trypsin and washed with PBS. The infected $\mathrm{GFP}^{+}$cells and uninfected cells were analyzed and quantified by a BD FACSVerse ${ }^{\mathrm{Tm}}$ flow cytometer (BD Biosciences, San Jose, CA, USA). The FACSuite (BD Biosciences, San Jose, CA, USA) and the Flowjo (Ashland, OR, USA) software were used for data analysis.

\section{Real time PCR}

For the quantification of late reverse transcription (RT) products, DNA was extracted from infected cells by using DNeasy Blood \& Tissue Kit (Qiagen, Hilden, Germany, USA). The early, intermediate, late RT products and HIV-1 2-LTR cycle DNA were quantified by a TaqMan real time PCR, and the relative copy numbers were normalized to reference gene PBGD by using the $\Delta \Delta \mathrm{Ct}$ method [29]. The integrated HIV-1 provirus copy was also measured by a method described previously by our group. Sample DNA was amplified using the TaqMan Universal PCR Real time Reagent (Life Technologies, Grand Island, NY, USA) in a StepOne Plus real time PCR instrument (Life Technologies, Grand Island, NY, USA). StepOne software was used for quantitative analysis.

\section{Western blot}

Proteins from cells were lysed with RIPA Lysis and Extraction Buffer (Thermos Fisher Scientific, Waltham, MA, USA). After being mixed with Laemmli buffer (BioRad, Hercules, CA, USA), protein samples were heated at $95^{\circ} \mathrm{C}$ for $10 \mathrm{~min}$. Protein samples were then separated by SDS-PAGE gel electrophoresis, and transferred onto PVDF membrane (Millipore, Billerica, MA, USA). After being probed with primary and secondary antibodies, protein bands in membranes were detected for chemiluminescence using SuperSignal ${ }^{\mathrm{m}}$ West Pico Chemiluminescent Substrate (Thermo Fisher, Rockford, lL, USA). The primary antibodies used were: anti-p21 ${ }^{\text {Cip1 }}$ (\#2947) and anti-phospho-SAMHD1 (Thr592) (\#89930) (Cell Signaling Technologies, Danvers, MA, USA); anti-SAMHD1 (\#12586-1-AP), anti-GAPDH (\#60004-1-Ig) and antiRRM2 (\#11661-1-AP) (Proteintech Group, Inc. Rosemont, IL, USA); anti-p53 (\#sc-126, Santa Crus, Dallas, TX, USA); anti-actin (\#A5441, Sigma-Aldrich, St. Louis, MO, USA) and anti-tubulin (\# N-356, Amersham, GE Healthcare, Pittsburgh, PA, USA). Western blot images were detected by the ChemiDoc XRS+ system (BioRad, Hercules, CA, USA), and image analysis was performed by using the Image Lab ${ }^{\text {tit }}$ software (BioRad, Hercules, CA, USA).

\section{siRNA transfection}

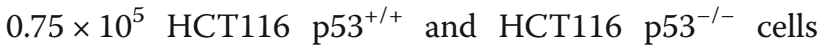
were cultured a 24 well plate overnight, siRNA transfections were performed using Lipofectamine ${ }^{\bullet}$ RNAiMAX $^{\mathrm{mm}}$ Transfection Reagent (Life Technologies, Grand Island, NY, USA) according to the manufacturer's instructions. After transfected with siRNA for 2 days, cells were cultured in DMEM without FBS for another $24 \mathrm{~h}$ before infection. siRNA transfection of hMDMs was performed two times with a recovery period of two days between transfections to ensure knockdown of target mRNA. siRNA knockdown was confirmed by Western blot. The Silencer Select validated siRNA siRNA p21 ${ }^{\text {Cip1 }}$ (\#4390824) and negative control non-target siRNA (\#4392420) were purchased from Life Technologies (Life Technologies, Grand Island, NY). siRNA p21 has a sequence of 5'-UAAAAUGUCUGACUCCUUGTT-3'. The FlexiTube siRNA p53 (\# SI02655170) was purchased from Qiagen (Qiagen, Hilden, Germany, USA) and has a sequence of 5'- ACUCCACACGCAAAUUUCCTT-3'.

\section{Statistical tests}

The Student's t-test was used to evaluate the difference in copy numbers of RT in real time PCR, data from luciferase assay in infection quantification, and protein levels in Western blot experiments. $P$-values between 0.01 and 0.05 , and less than 0.01 were considered significant and highly significant, respectively.

\section{Result}

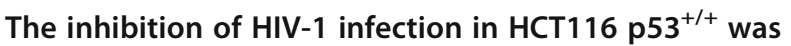
increased with cell cycle changed from cycling to noncycling status

It was found by our group that the infection of MLV vector based retrovirus was inhibited significantly in non-cycling HCT116 $\mathrm{p}^{2} 3^{+/+}$, while the inhibition was attenuated in non-cycling HCT116 p53 ${ }^{-/-}$cells [26]. To investigate whether p53 also inhibits HIV-1 infection 
depending on cell cycle status, non-cycling HCT116

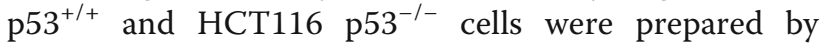
serum starvation for $24 \mathrm{~h}$, then the cell cycle statuses of both cycling and non-cycling cells were analyzed by flow cytometry after PI staining and EdU incorporation. The majority of HCT116 $\mathrm{p} 53^{+/+}$and HCT116 $\mathrm{p} 53^{-/-}$ cells were in S and G2 phases when cultured in complete medium with 10\% FBS (Fig. 1a). After being cultured in

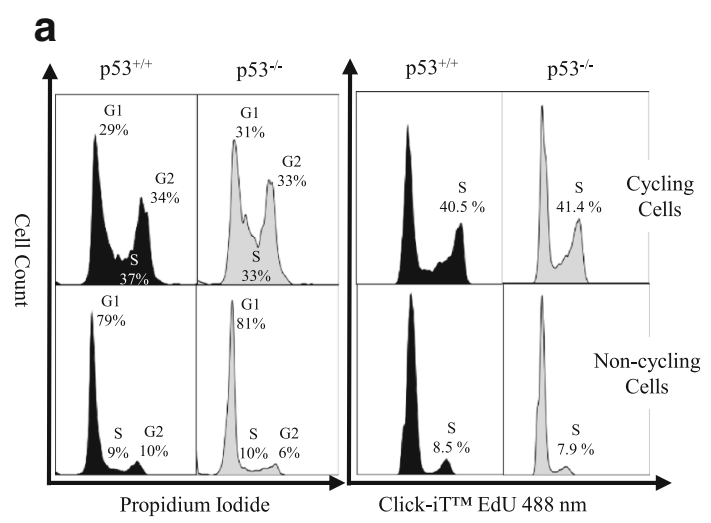

b

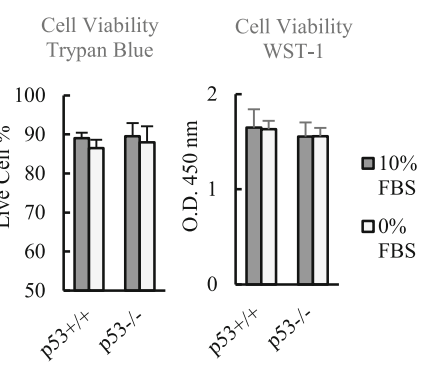

C

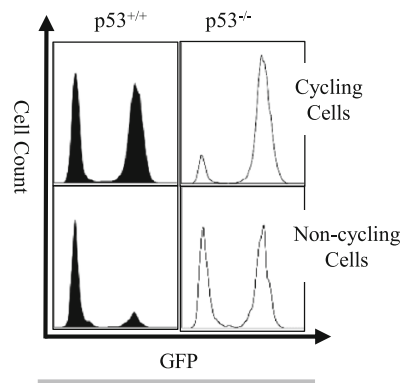

HIV-1 GFP ${ }^{+}$(2.0 MOI) d

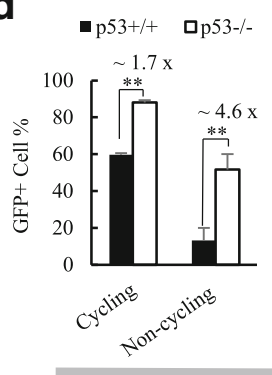

HIV-1 $\mathrm{GFP}^{+}(2.0 \mathrm{MOI})$
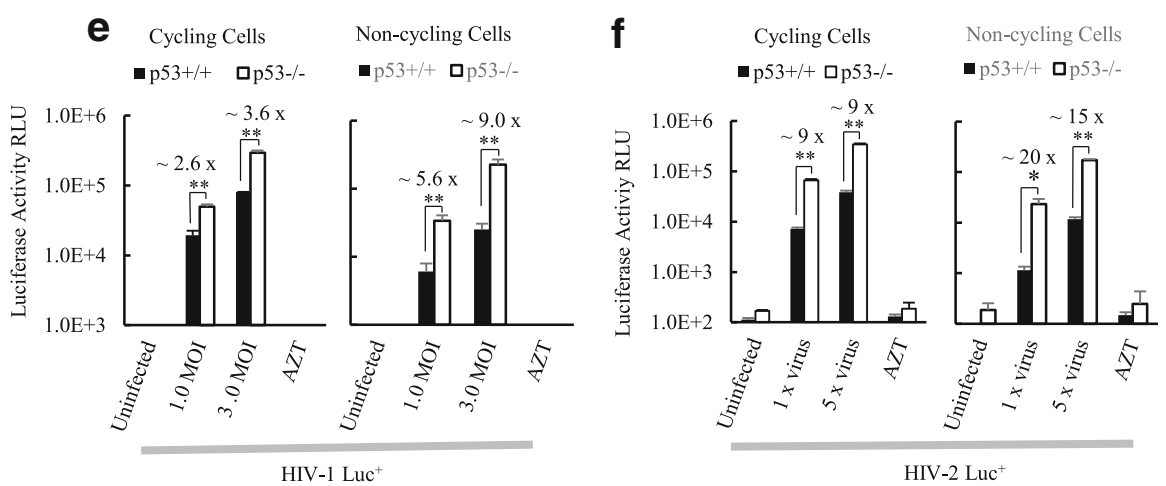

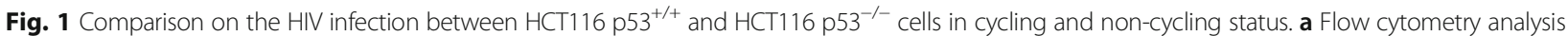

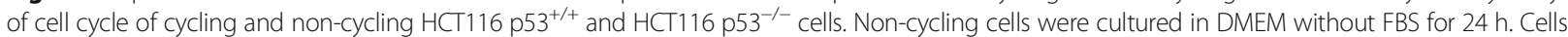
are stained with propidium iodide (PI) (Left). S phase cell percentages in cycling and non-cycling HCT116 p53 ${ }^{+/+}$and HCT116 p53 $3^{-/-}$cells were also analyzed by Click-iT TM Plus EdU Flow Cytometry Assay (Right). b Cell viabilities of both cycling and non-cycling HCT116 p53 ${ }^{+/+}$and HCT116 p53 $3^{-1-}$ cells were measured by Trypan blue exclusion test (Left) and WST-1 assay (Right). c Flow cytometer analysis of infection $24 \mathrm{~h}$ after infection by VSV-G pseudotyped HIV-1 GFP ${ }^{+}$virus in cycling and non-cycling HCT p53 $3^{+/+}$and HCT116 p53 $3^{-/-}$cells. Uninfected cells were shown as the 1st peak, and the infected GFP+ cells were shown as the 2nd peak. $\mathbf{d}$ Quantification of HIV-1 GFP ${ }^{+}$infection in cycling and non-cycling HCT116 p53 $3^{+/+}$and HCT116 p53 $3^{-/-}$cells. e Quantification of infection of VSV-G pseudotyped HIV-1 Luc ${ }^{+}$virus in cycling and non-Cycling HCT116 p53 ${ }^{+/+}$and HCT116 $\mathrm{p5}^{-/-}$cells. Luciferase assay for VSV-G pseudotyped HIV-1 Luc ${ }^{+}$virus was performed at $24 \mathrm{~h}$ after infection. f Quantification of infection of VSV-G pseudotyped HIV-2 Luc ${ }^{+}$virus in cycling and non-cycling HCT116 p53 $3^{+/+}$and HCT116 p53 $3^{-/}$cells. $20 \mu \mathrm{l} \mathrm{of} \mathrm{transfection}$ supernatant of pHIV-2 Luc ${ }^{+}$and pVSV-G was used in 1 x virus infection; $100 \mu \mathrm{l}$ of transfection supernatant was used in $5 \times$ virus infection. Luciferase assay was performed at $48 \mathrm{~h}$ after HIV-2 Luc $^{+}$infection. The results represented a triplicate experiment. In Student's t-test, $p$ value $<0.05$ is indicated by * $p$ value $<0.01$ is indicated by ** 
DMEM without FBS for $24 \mathrm{~h}$ both HCT116 $\mathrm{p} 53^{+/+}$cells and HCT116 $\mathrm{p}^{-/-}$cells became non-cycling cells, with very low percentages of cell populations in S phase and G2 phase $(\leq 10 \%)$ (Fig. 1a). The cell viabilities of both cycling and non-cycling HCT116 $\mathrm{p} 53^{+/+}$and HCT116 $\mathrm{p} 53^{-/-}$cells were analyzed by trypan blue exclusion test and by WST-1 assay (Fig. 1b). The results showed that there were no cell viability differences between cycling and non-cycling cells

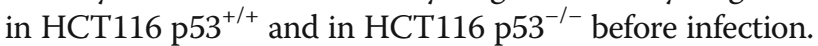

Both cycling and non-cycling HCT116 $\mathrm{p}^{+/+}$and HCT116 $\mathrm{p}^{-/-}$cells were infected by 2.0 MOI VSV-G pseudotyped HIV-1 $\mathrm{GFP}^{+}$virus (Fig. 1c and d). In cycling cell status both HCT116 p53 $3^{+/+}$and HCT116 $\mathrm{p}^{-/-}$were highly permeable to HIV-1 infection, and the infection in

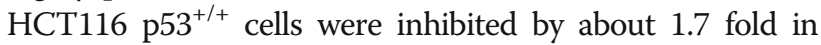
comparison to HCT116 $\mathrm{p}^{-/-}$cells. However the fold of inhibition in HCT116 p53 ${ }^{+/+}$increased to 4.6 times in noncycling cells (Fig. 1c and d). To confirm this observation, both cycling and non-cycling HCT116 $\mathrm{p}^{+/+} 3^{+}$and HCT116 $\mathrm{p} 53^{-/-}$cells were infected by 1.0 and $3.0 \mathrm{MOI}$ of VSV-G pseudotyped HIV-1 $\mathrm{Luc}^{+}$virus respectively. In $1.0 \mathrm{MOI}$ HIV-1 infection, the inhibition changed from about 2.6 fold to 5.6 fold, and in $3.0 \mathrm{MOI}$ infection, the observed inhibition in HCT116 $\mathrm{p}^{+/++}$cells increased from 3.6 fold to 9 fold in comparison to HCT116 $\mathrm{p} 53^{-/-}$cells when cell cycle switched from cycling to non-cycling status (Fig. 1e). The amount of infection was dependent on virus dosage and no luciferase activities were detected in both uninfected cells and AZT treated cells. These results indicated the HIV-1 infection can be blocked by the presence of p53, and p53 dependent inhibition was increased with cell cycle change from cycling to non-cycling status.

In order to investigate whether HIV-2 infection is also inhibited by p53 dependent on cell cycle status, VSV-G pseudotyped HIV-2 $\mathrm{Luc}^{+}$virus was used to infect both cycling and non-cycling HCT116 $\mathrm{p} 53^{+/+}$and HCT116 $\mathrm{p} 53^{-/-}$ cells (Fig. 1f). HIV-2 infection was significantly inhibited in HCT116 $\mathrm{p}^{+/+}$in comparison to HCT116 p53 ${ }^{-/-}$cells. The inhibition in HCT116 $\mathrm{p}^{+/++}$was about 9 folds in cycling cells when infected with $1 \mathrm{x}$ and $5 \times \mathrm{HIV}-2 \mathrm{Luc}^{+}$viruses respectively, and inhibition in HCT116 $\mathrm{p} 53^{+/+}$ was about 20 and 15 folds in non-cycling cells when infected with $1 \times$ and $5 \times$ HIV-2 Luc ${ }^{+}$viruses respectively (Fig. 1f). This finding suggested the inhibition to overall HIV-2 infection was increased compared to the inhibition to HIV-1 infection in HCT116 $\mathrm{p}^{+/ /+}$, and the inhibition to HIV-2 was also increased with cell cycle change from cycle to non-cycling status.

\section{HIV-1 reverse transcription was inhibited in $\mathrm{HCT} 116 \mathrm{p} 53^{+/+}$

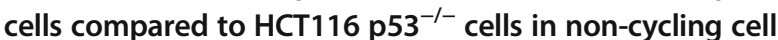 cycle status}

We found previously that p53 inhibited retrovirus reverse transcription [26]. To identify whether p53 dependent
HIV-1 inhibition in non-cycling cells also happened at reverse transcription, a TaqMan real time PCR was used to quantify HIV-1 reverse transcription (RT) late product in infected cells. It was found there was no difference in amount of RT products between cycling HCT116 p53 and cycling HCT116 $\mathrm{p} 53^{-/-}$cells at $16 \mathrm{~h}$ post infection, however HIV-1 RT product was decreased about 2.1 times in HCT116 $\mathrm{p}^{2} 3^{+/+}$cells compared to HCT116 $\mathrm{p} 53^{-/-}$cells in non-cycling cells (Fig. 2a). In order to identify whether the decrease of RT product in HCT116 $\mathrm{p}^{+/++}$cells was either due to the inhibition in the process in viral cDNA synthesis by reverse transcriptase or because of possible degradation of virus cDNA by nucleases in infected cells, the amount of remaining late RT product was quantified at $1.5 \mathrm{~h}, 3.0 \mathrm{~h}$ and $4.5 \mathrm{~h}$ after cells were treated with the reverse transcriptase inhibitor EFA at $12 \mathrm{~h}$ post infection. No difference was observed in the percentages of virus cDNA degradation between non-cycling HCT116 $\mathrm{p} 53^{+/+}$ and HCT116 $553^{-/-}$cells after blocking reverse transcriptase by EFA (Fig. 2b). This result indicated that the observed p53 dependent inhibition occurred in the synthesis of virus cDNA by HIV-1 reverse transcriptase. In a separate HIV-1 infection experiment, the amount of virus cDNA at different reverse transcription stages were quantified (Fig. 2c-e). HIV-1 early, intermediate and late reverse transcription products were found to be consistently decreased in non-cycling HCT116 $\mathrm{p}^{+/+}$cells compared to non-cycling HCT116 p53 ${ }^{-/-}$cells over $8 \mathrm{~h}, 16 \mathrm{~h}$ and $24 \mathrm{~h}$ after infection (Fig. 2c-e). HIV-1 2-LTR cycle DNA and integration were also quantified (Fig. $2 \mathrm{f}$ and g). The amount of decrease of 2-LTR cycle DNA and integrated HIV-1 provirus copy in non-cycling HCT116 $\mathrm{p}^{+/+}$cells in comparison to non-cycling HCT116 $\mathrm{p}^{-/-}$cells were about 2 times less, which are similar to the observed level of inhibitions in different RT stages. These results indicated that the block of HIV-1 infection in non-cycling

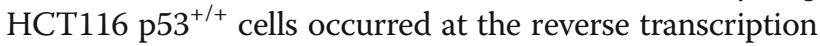
stage mostly by a mechanism involving in the processing of HIV-1 reverse transcription.

\section{The $\mathrm{p} 53$ and its downstream gene $\mathrm{p} 21$ proteins were increased in $\mathrm{HCT} 116{\mathrm{p} 53^{+/+}}^{+}$when cell cycle was changed from cycling to non-cycling status}

To investigate the p53 gene function change when cell cycle was changed from cycling to non-cycling status, and its response to HIV-1 infection, Western blot experiments were carried out to analyze the changes of p53, phosphorylated p-p53(S15) and the p53 downstream gene p21 (Fig. 3a and b). It was found that both the levels of p53 protein and p21 protein were significantly increased in non-cycling HCT116 $\mathrm{p} 53^{+/+}$cells in comparison to cycling HCT116 $\mathrm{p} 53^{+/+}$cells (Fig. 3a and b). p-p53 (S15) was slightly elevated at $1 \mathrm{~h}$ after HIV-1 infection in cycling HCT116 $\mathrm{p}^{+/+}$cells, but no difference 

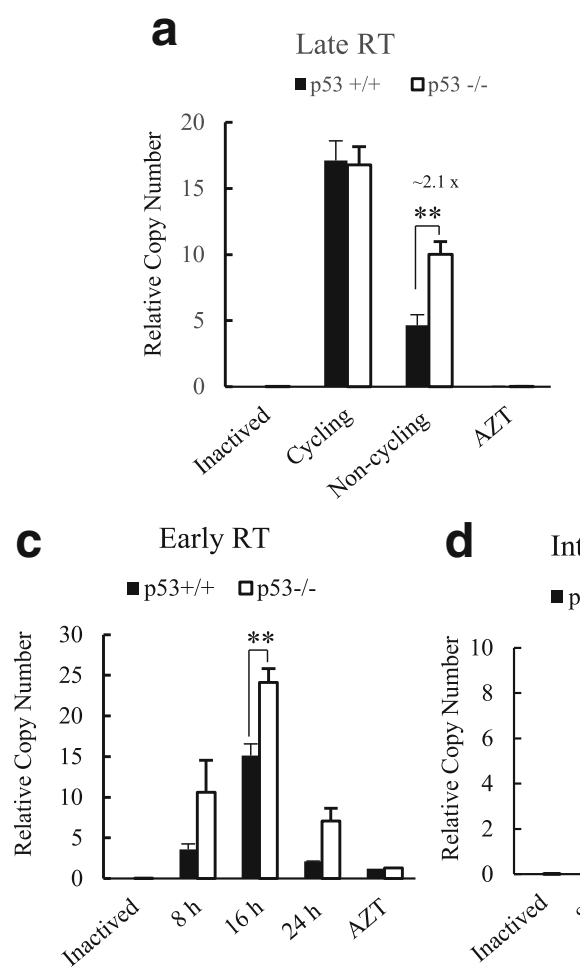

d

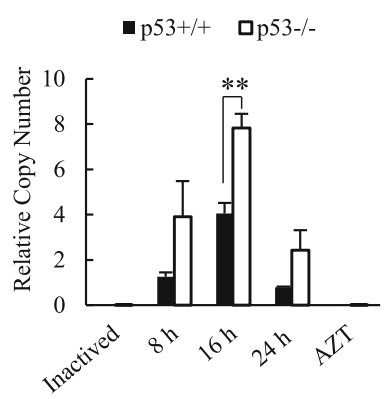

b Degradation of Late RT after EFA Treatment

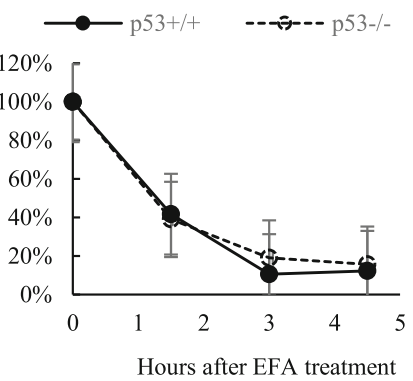

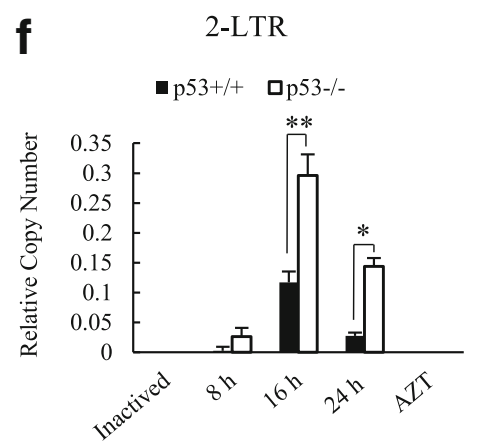

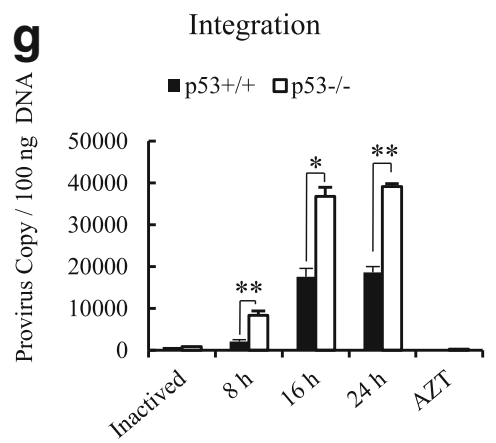

Fig. 2 Comparison of HIV-1 reverse transcription and viral cDNA degradation in infected HCT116 p53 $3^{+/+}$and HCT116 p53 $3^{-/-}$cells. a Quantification

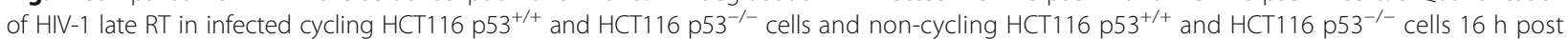
infection. $\mathbf{b}$ Evaluation of HIV cDNA degradation after treatment of the reverse transcriptase inhibitor EFA. The relative copy number of HIV-1 late RT product (viral CDNA) was quantified by TaqMan real time PCR. At each time point, the remaining viral cDNA (\%) was calculated from the copy of CDNA per cell treated with EFA divided by the copy of CDNA per untreated cell. Time indicates the number of hours after the addition of EFA. The results represented a triplicate experiment. Comparison of HIV-1 CDNA at different stages of virus replication between non-cycling HCT116 $\mathrm{p} 53^{+/+}$and non-HCT116 $553^{-/-}$cells at $8 \mathrm{~h}, 16 \mathrm{~h}$ and $24 \mathrm{~h}$ post infection were performed. c Early RT. d Intermediate RT. e Late RT. f 2-LTR cycle DNA. $\mathbf{g}$ Integration. Both inactived virus and AZT treatment were used as negative control. Relative RT copy numbers were quantified by a TaqMan real time PCR. In Student's t-test, $p$ value $<0.05$ is indicated by *; $p$ value $<0.01$ is indicated by **

of p-p53 (S15) was found in non-cycling HCT116 p53 cells. Western blots were also performed on cycling and non-cycling HCT116 $\mathrm{p}^{-/-}$cells in the course of HIV-1 infection (Fig. 3a and b). The expression level of p21 was low in HCT116 $\mathrm{p}^{-/-}$cells and there were no significantly difference in $\mathrm{p} 21$ protein levels in HCT116 $\mathrm{p} 53^{-/-}$cells between cycling and non-cycling cells. This data suggests that the cell cycle status change resulting from serum starvation induced p53 expression, which in turn regulated the expression of p21 in HCT116 $\mathrm{p} 53^{+/+}$cells. However the increase of p21 resulting from cell cycle change did not occur in HCT116 $\mathrm{p}^{-1 /}$ cells, which is in concordance with the lack of regulation by a functional p53.

\section{The analysis of restriction to HIV-1 infection by $\mathrm{p} 53$ and}

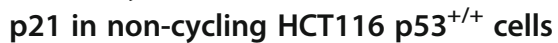

It has been shown that p21 inhibits HIV reverse transcription by regulating cellular dNTPs level in differentiated 

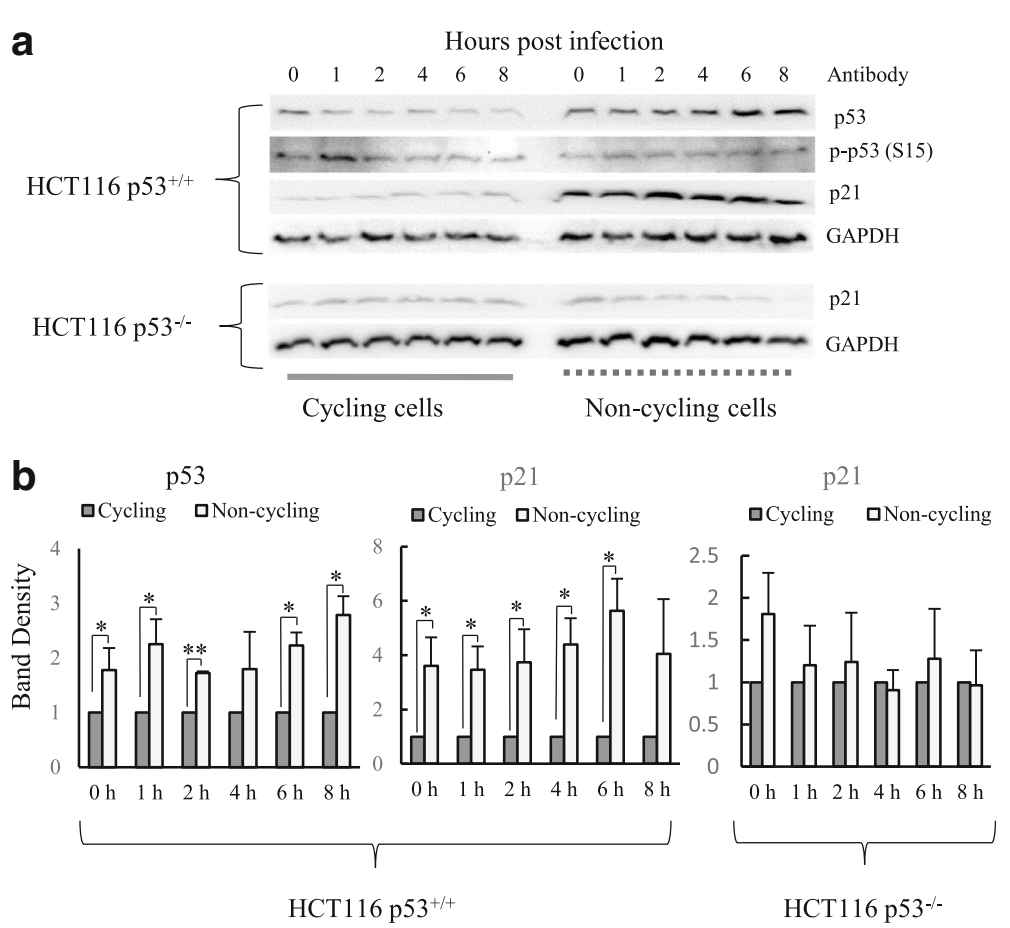

Fig. 3 Western Blot Analysis of p53, p-p53 (S15) and p21 proteins in HIV-1 infected HCT116 p53 ${ }^{+/+}$and HCT116 p53 $3^{-/-}$cells when cells changes from cycling cells to non-cycling cells. a Western blot of p53, p-p53 (S15) and p21 in HIV-1 infected cycling and non-cycling HCT116 p53 ${ }^{+/+}$cells and HCT116 p53 $3^{-/-}$cells. b Quantification of Western blot of p53, p-p53 (S15) and p21 proteins. The results represented a duplicate experiment. In Student's t-test, $p$ value $<0.05$ is indicated by *

macrophages. p21 was found to phosphorylate SAMHD1 at Thr592 [20], which inactivates its activity to degrade cellular dNTPs. p21 was also reported to down regulate expression of RNR2 [17], an enzyme responsible for cellular synthesis of dNTPs. Western blot experiments were carried out to compare p21, SAMHD1, pSAMDH1(T592) and RNR2 protein levels between non-cycling HCT116

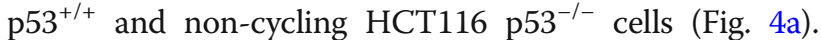
The levels of p21 protein were significantly higher over the course of HIV-1 infection in non-cycling HCT116 $\mathrm{p} 53^{+/+}$in comparison to non-cycling HCT116 $\mathrm{p} 53^{-/-}$ cells (Fig. 4a and b). There was no difference found in overall SAMHD1 levels (Fig. 4a and c), however both pSAMDH1 (T592) and RNR2 protein levels were elevated over multiple time points over HIV-1 infection in non-cycling HCT116 $\mathrm{p}^{+/++}$in comparison to non-cycling HCT116 $\mathrm{p}^{-/-}$cells (Fig. 4a and d, e), even though the differences were not statistically significant.

\section{siRNA knockdown of either p53 or p21 rescued HIV-1 reverse transcription from the inhibition in non-cycling HCT116 $\mathrm{p}^{+/+}$cells}

To further verify that the increase in p53 and p 21 at protein level was responsible for the inhibition of HIV-1 reverse transcription in non-cycling cells, HCT116 $\mathrm{p} 53^{+/+}$ cells were transfected with either p53 siRNA or p21
siRNA. The non-targeting (NT) siRNA was used as negative control. After $48 \mathrm{~h}$ the medium were replaced with DMEM without FBS and cultured for another $24 \mathrm{~h}$, and then siRNA transfected cells were infected with HIV-1 virus. As shown in Fig. 5a, both knockdown of p53 and knockdown of p21 by siRNA transfection were confirmed by Western blot experiment (Fig. 5a). Transfection with p21 siRNA resulted in knockdown of p21 to 13\% (Fig. 5b). Transfection with p53 siRNA also led to knockdown of p21 to $18 \%$. Transfection with p53 siRNA resulted in knockdown of p53 to $14 \%$ (Fig. 5c). To analyze the potential role of p53 and p21 in the regulation of genes responsible for maintaining host cell dNTPs pool size, SAMHD1, pSAMHD1(T592) and RNR2 protein levels were compared between HCT116 $\mathrm{p}^{+/+}$cells transfected with p53 or p21 gene specific siRNA and nontargeting siRNA (Fig. 5a). It was found that the knockdown of p53 increased both RNR2 and pSAMHD1 (T592), and the knockdown of p21 increased RNR2 and increased pSAMHD1 (T-592) slightly as well. Either the knockdown of p53 or the knockdown of p21 did not change SAMHD1 at protein level significantly (Fig. 5a). The cell cycle status after siRNA treatment was also tested by Click-iT ${ }^{\mathrm{max}}$ Plus EdU Flow Cytometry Assay. There were a minor increase in S phase in siRNA p21 treated cells (15.5\%) and siRNA p53 treated cells (13.5\%) 
a

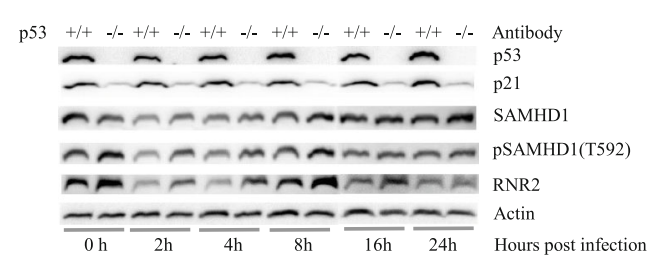

C

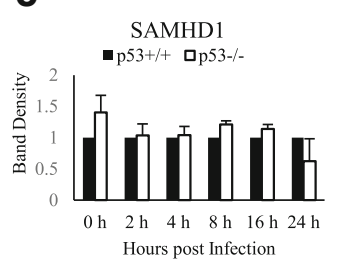

d

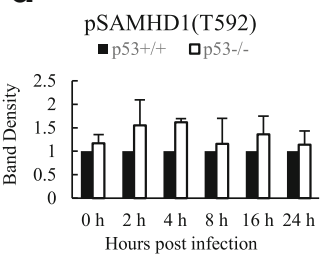

b

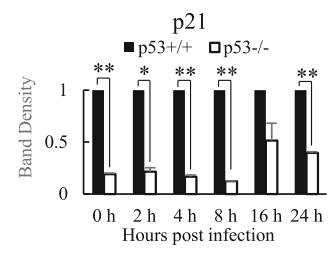

e

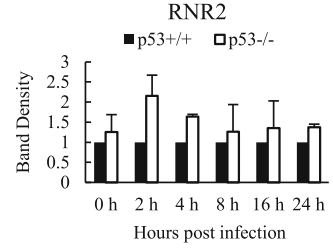

Fig. 4 Comparative Analysis of p21, SAMHD1, pSAMHD1 (T592) and RNR2 between non-cycling HCT116 p53 $3^{+/+}$cells and non-cycling HCT116 p53-/cells in HIV-1 infection. a Western blot of p21, SAMHD1, pSAMHD1 (T592) and RNR2 between non-cycling HCT116 p53 ${ }^{+/+}$cells and non-Cycling HCT116 p53 $3^{-/-}$cells in HIV-1 infection. b Quantitative analysis of p21 protein between non-cycling HCT116 p53 ${ }^{+/+}$cells and non-cycling HCT116 p53 ${ }^{-/-}$cells in HIV-1 infection. c Quantitative analysis of SAMHD1 protein between non-cycling HCT116 p53 ${ }^{+/+}$cells and non-cycling HCT116 p53 ${ }^{-/-}$cells in HIV-1 infection. d Quantitative analysis of pSAMHD1 (T592) protein between non-cycling HCT116 p53 ${ }^{+/+}$cells and non-cycling HCT116 p53 ${ }^{-/-}$cells in HIV-1 infection. e Quantitative analysis of RNR2 protein between non-cycling HCT116 p53 ${ }^{+/+}$cells and non-cycling HCT116 p53 ${ }^{-/-}$cells in HIV-1 infection. The results represented a duplicate experiment. In Student's t-test, $p$ value $<0.05$ is indicated by * $p$ value $<0.01$ is indicated by **

compared to siRNA NT treatment (12.9) (Fig. 5d). siRNA knockdown of p21 in non-cycling HCT116 p53 ${ }^{+/+}$cells significantly increased infection of $\mathrm{HIV}-1 \mathrm{Luc}^{+}$virus, and siRNA knockdown of p53 in non-cycling HCT116 p53 ${ }^{+/+}$ cells also increased infection of HIV-1 $\mathrm{Luc}^{+}$virus but the increase was not statistically significant (Fig. 5e). Meanwhile, either p53 siRNA or p21 siRNA treatment significantly increased HIV-1 reverse transcription in noncycling HCT116 ${\mathrm{p} 53^{+/+}}$cells (Fig. 5f). The above data indicated that it was the elevated $\mathrm{p} 53$ protein or $\mathrm{p} 21$ protein in non-cycling HCT116 $\mathrm{p}^{+/+}$cells that caused the inhibition in HIV-1 reverse transcription.

\section{The inhibition of HIV infection by p53 and its downstream gene p21 in hMDMs}

To identify whether p53 and p21 impact HIV-1 infection in its natural host cells, VSV-G pseudotyped HIV-1 Luc ${ }^{+}$ was used to infect hMDMs. Protein levels of p53, pp53(S-15) and p21 were analyzed by Western blot at multiple time points during the early stage of HIV-1 replication (Fig. 6a and b). In donor 1, p53 protein level was increased at $1 \mathrm{~h}$ after infection. The amount of $\mathrm{p} 21$ protein started to increase at $2 \mathrm{~h}$ post infection, and higher amounts of p21 proteins were found as early as $4 \mathrm{~h}$ and $8 \mathrm{~h}$ post infection. In donor 2 , p21 protein was also increased at time points of $8 \mathrm{~h}$ and $16 \mathrm{~h}$ after infection, and there was minor increase in p53 proteins at time points of $4 \mathrm{~h}, 8 \mathrm{~h}$ and $16 \mathrm{~h}$. No noticeable changes were observed in p-p53 (S-15) in infected hMDMs. Interestingly, p21 protein levels were increased in hMDMs in both donors at an early stage of HIV-1 replication, approximately when reverse transcription is in process. This result strongly suggests the role of p21 in the restriction to early stage of HIV-1 replication in hMDMs.

The function of p53 and p21 in HIV-1 infection was further examined by siRNA experiments. After the siRNA transfection, p21 protein level dropped about $28 \%$ in cultured hMDMs (Fig. 6c and d). The knockdown of p21 increased both RNR2 and pSAMHD1(T592), and HIV-1 infection increased significantly (Fig. 6c and e). After siRNA transfection, p53 protein level dropped about $40 \%$ in cultured hMDMs. The knockdown of p53 increased pSAMHD1(T592), and HIV-1 infection was increased but not statistically significant (Fig. 6c-e). There were no obvious changes in RNR2 protein levels after knockdown of p53, and knockdown of either p21 or p52 did not alter total SAMHD1 protein levels.

p21 was previously found to restrict HIV-2 infection $[15,16]$. The Vpx protein from HIV-2 is able to degrade cellular restriction factor SAMHD1 [30], while p21 can inactivate SAMHD1 by phosphorylation [20]. To investigate the role of p21 in HIV-2 infection, hMDMs were transfected with p21 siRNA, then infected by HIV-2 Luc ${ }^{+}$virus. In this experiment siRNA transfection was able to knockdown p21 to about 52\% (Fig. 6f, g). In control hMDMs transfected with non-targeting siRNA, HIV-2 infection resulted in the decrease in SAMHD, and the levels of pSAMHD1 (T592) were almost undetectable before and after HIV-2 infection (Fig. 6f). p21 siRNA knockdown did not change SAMHD1 levels but greatly increased pSAMHD1 (T592) in both HIV-2 infected and uninfected hMDMs (Fig. 6f). Finally it was found that 
a

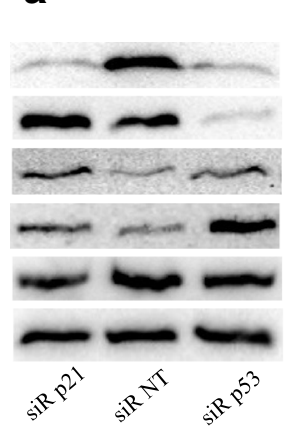

b

Antibody

p21

p53

RNR2

pSAMHD1 (T-592)

SAMHD1

GAPDH

.

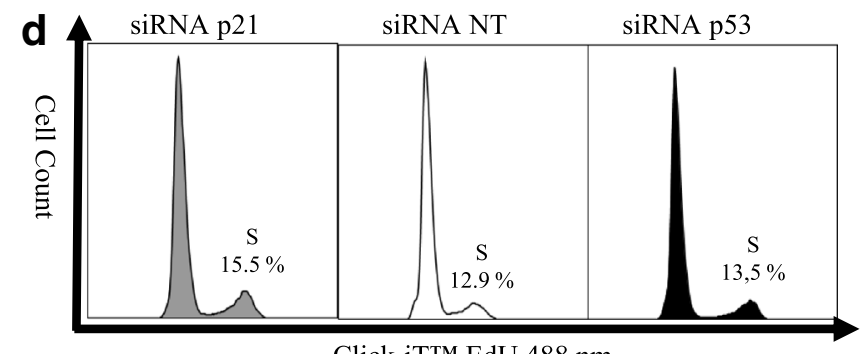

Click-iT $^{\mathrm{TM}}$ EdU $488 \mathrm{~nm}$
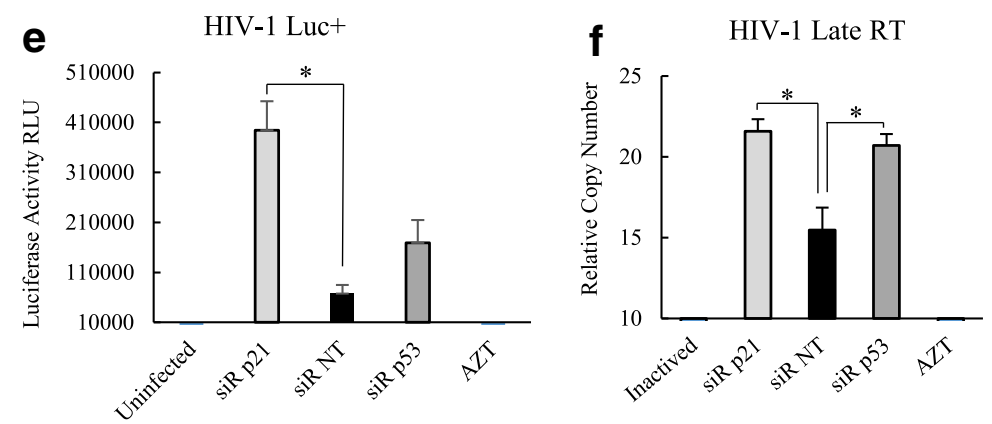

Fig. 5 The analysis of HIV-1 infection after siRNA knockdown of p53 and p21 in non-cycling HCT116 p53 ${ }^{+/+}$cells. a Western blot of p53, p21,

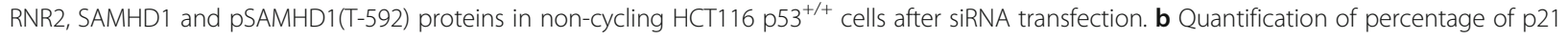
after siRNA knockdown of p21 and siRNA knockdown of p53. c Quantification of percentage of p53 after siRNA knockdown of p21 and siRNA knockdown of p53. d Cell cycle analysis after siRNA transfections by Click-iT'M Plus EdU Flow Cytometry Assay. e Quantification of infection in non-cycling HCT116 p53 ${ }^{+/+}$cells after siRNA knockdown of p21 and siRNA knockdown of p53. f Quantification HIV-1 RT in non-cycling HCT116 p53 $3^{+/+}$cells after siRNA knockdown of p21 and siRNA knockdown of p53. $2.0 \mathrm{MOI}$ HIV-1 was used to infect non-cycling HCT116 p53 $3^{+/+}$cells in the quantification of infection and late RT. The non-targeting (NT) siRNA was used as negative control. HIV-1 RT was quantified by TaqMan real time PCR at $16 \mathrm{~h}$ post infection. The results represented a triplicate experiment. In Student's t-test, $p$ value $<0.05$ is indicated by *

knockdown p21 in hMDMs significantly increased HIV-2 infection (Fig. 6h). This result also suggested that the degradation of SAMHD by HIV-2 Vpx was independent from phosphorylation of SAMHD1 resulted from $\mathrm{p} 21$ knockdown by siRNA in hMDMs.

\section{Discussion}

The permissiveness of HIV infection is dependent on the host cell's cell cycle status. Activated macrophages and proliferating $\mathrm{CD}^{+} \mathrm{T}$ lymphocytes are highly susceptible to infection, however resting $\mathrm{CD}^{+}{ }^{+} \mathrm{T}$ cells and quiescent macrophages are largely non-permissive to HIV-1 replication [31-33]. Early studies demonstrated that restriction to HIV-1 infection in non-cycling quiescent macrophages and resting $\mathrm{CD}^{+} \mathrm{T}$ cells occurred during reverse transcription [33-35]. Korin found HIV infection was successful only in $\mathrm{CD}_{4}^{+} \mathrm{T}$ cells that transited into the G1b phase of the cell cycle [36]. Mlcochova et al.... reported recently that HIV-1 infection was highly susceptible in stimulated G1-like phase macrophages, which are characterized by an increase in D-type cyclins, upregulation of CDK1 with subsequent SAMHD1 T592 phosphorylation [37]. Histone deacetylase inhibitors (HDACi) treatment blocked the transition from G1-like phase to a non-permissive state. The block by HDACi in hMDMs was associated with increased expression of p53 [37]. p21 is a well-known CDK 

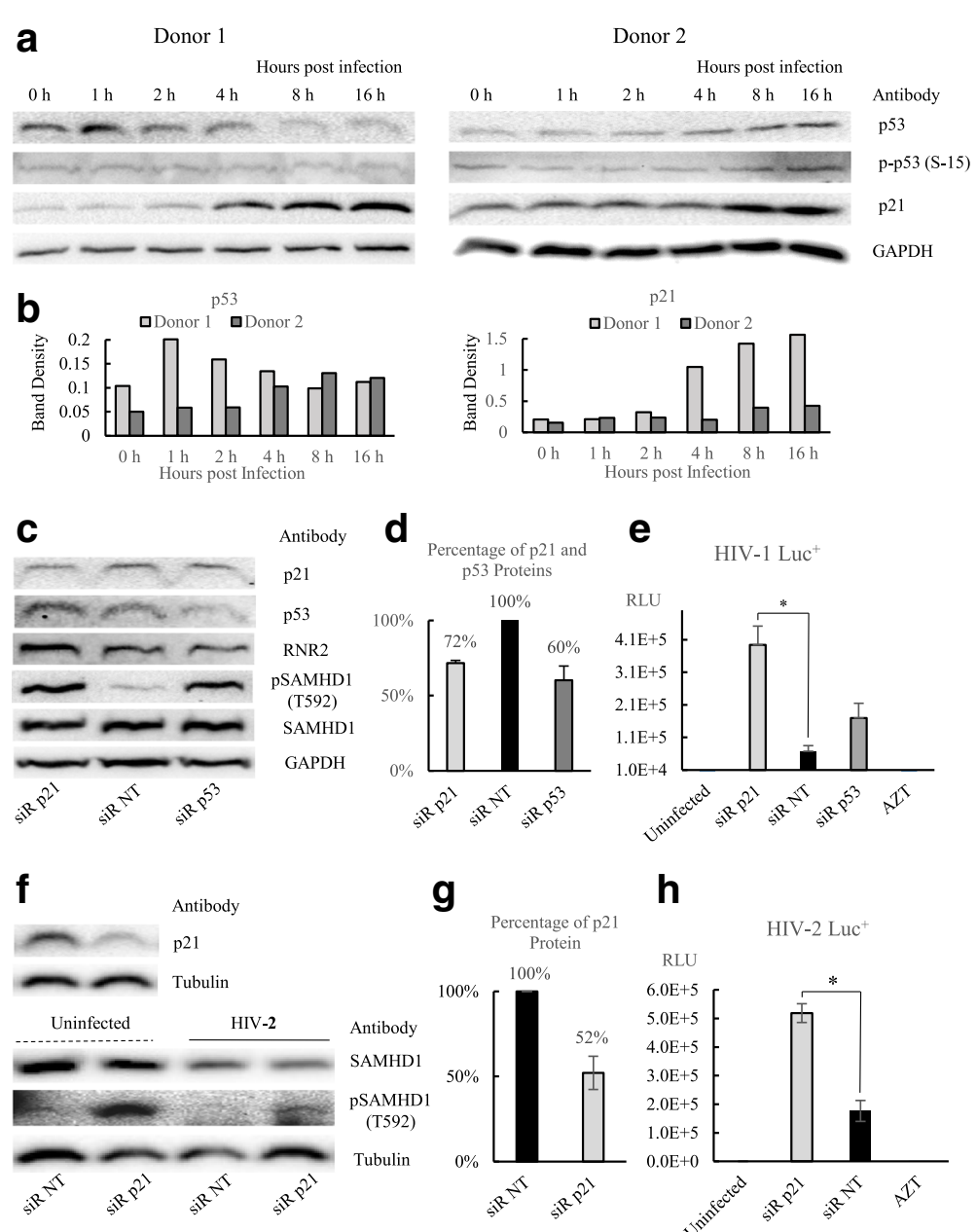

Fig. 6 Analysis of function of p53 and its downstream gene p21 during HIV infection in hMDMs. a and b Analysis of p53, p-p53 (S15) and p21 proteins in hMDMs after HIV-1 infection by Western blot. 3.0 MOI VSV-G pseudotyped HIV-1 GFP ${ }^{+}$virus was used to infect $0.5 \times 10^{6} \mathrm{hMDMs}$ in a 24 well plate, Results from two different donors were shown. c Western blot analysis of SAMHD1, pSAMHD1 (T592) and RNR2 after siRNA knockdown of p53 and siRNA knockdown of p21 in hMDMs. $\mathbf{d}$ Percentages of p21 protein and p53 protein after siRNA knockdown. The non-targeting (NT) siRNA was used as negative control. e Quantification of HIV-1 Luc infection after siRNA knockdown of p21 and siRNA knockdown of p53 in hMDMs. $\mathbf{f}$ Analysis of SAMHD1 and PSAMHD1(T592) in HIV-2 infection after siRNA knockdown of p21 in hMDMs. $\mathbf{g}$ The percentage of p21 after siRNA knockdown in hMDMs. $\mathbf{h}$ Quantification of HIV-2 infection in hMDMs transfected with p21 siRNA and non-targeting siRNA. The non-targeting (NT) siRNA was used as negative control. Luciferase assay was performed at $48 \mathrm{~h}$ after HIV-2 Luc ${ }^{+}$infection. The results represented a triplicate experiment. In Student's t-test, $p$ value $<0.05$ is indicated by *

inhibitor, and it functions to block cell cycle transition at G1 when being activated [38]. Our results suggest that the response of p53 and its downstream gene p21 to cell cycle status changes will significantly impacted the host cell's permissiveness to HIV-1 infection.

We found that HIV-1 infection was inhibited in HCT $\mathrm{p} 53^{+/+}$cells in comparison to HCT $\mathrm{p} 53^{-/-}$cells. In cycling cells inhibitions to HIV-1 infection were 1.7 fold (2.0 MOI HIV-1 GFP ${ }^{+}$), 2.6 fold (1.0 MOI HIV-1 Luc+) and 3.6 fold (3 MOI HIV-1 Luc+) respectively, while in non-cycling cells inhibitions were more than doubled, i.e. 4.6 fold (2.0 MOI HIV-1 GFP ${ }^{+}$), 5.6 fold (1.0 MOI HIV-1 Luc+) and 9.0 fold (3.0 MOI HIV-1 Luc+) respectively. It has been known that p53 inhibits HIV-1 infection at transcription level $[3,5,6]$, which is the inhibition to the late stage of HIV replication and will applies to HIV-1 infections in both cycling and non-cycling cells. Our findings pointed out that the increased inhibition in HCT $\mathrm{p}^{+/+}$non-cycling cells was due to the additional block in the reverse transcription.

p53 expression was elevated when the cell cycle switched from cycling to non-cycling after serum starvation (Fig. 3), which agrees with the previous findings by both Shang et al... and Shi et al that serum starvation can induce p53 expression [39, 40]. The increased p53 expression subsequently induced the expression of its downstream gene p21. The siRNA knockdown experiment confirmed that p53 and p21 were responsible for the observed inhibition 
in HIV-1 reverse transcription (Fig. 4). We also found for the first time that p53 and p21 increased at protein level in hMDMs at very early time (from 1 to $8 \mathrm{~h}$ after infection) during HIV-1 infection. These data strongly indicated that p53 and its downstream gene p21 play an important role in the restriction of HIV-1 early stage replication in natural host cells.

In this study we also investigated the host cell's restriction to HIV infection by regulating the level of cellular dNTPs. SAMHD1 is a cellular dNTPase that restricts HIV infection by lowering cellular dNTPs to a level required for reverse transcription. RNR2 is responsible for the de novo synthesis of dNTPs. The two main enzymes controlling dNTP pool sizes are adjusted to the requirements of DNA replication following cell cycle in mammalian cells [41]. Allouch et al.... reported after p21 was induced by immune complex aggregation of FcyRs in macrophages, it restricted HIV reverse transcription by blocking the synthesis of dNTPs through the inhibition of the expression of RNR2 [17, 21]. Pauls et al found that in macrophages differentiated by M-CSF p21 blocked the phosphorylation of SAMHD1 [20]. Phosphorylation inactivates the dNTPase activity of SAMHD1 [20]. We found that the knockout of p53, and siRNA knockdown of p53 and p21 were associated with the increase protein levels of both RNR2 and pSAMHD1 (T592) in non-cycling HCT116 p53 ${ }^{+/+}$cells (Figs. 4 and 5). Furthermore, the siRNA knockdown of p21 in hMDMs increased protein levels of both RNR2 and pSAMHD1 (T592) (Fig. 6c). Our data highly suggested that p21 could suppress the expression of RNR2 and block the phosphorylate SAMHD1 simultaneously in non-cycling cells so as to restrict HIV-1 infection through regulating cellular dNTPs. We also found that siRNA knockdown of p53 induced pSAMHD1 (T592) in both HCT116 p53 ${ }^{+/+}$cells and hMDMs. (Figs. 5 and $6 \mathrm{c}$ ). Micochova reported recently that HDACi can block HIV-1 infection by inhibiting phosphorylation of SAMHD1 via p53 activation [37]. It remains to be elucidated whether p53 can inhibit the phosphorylation of SAMHD1 independent of p21.

p21 may also inhibit HIV infection by pathways other than through regulating the cellular level of dNTPs. p21 was found to inhibit reverse transcription by phosphorylating HIV-1 reverse transcriptase [18]. Others showed that the restriction to HIV infection by $\mathrm{p} 21$ was associated with Vpr [42-44]. We found that p53 and p21 inhibited HIV-2 infection in both cycling and non-cycling HCT116 $\mathrm{p} 53^{+/+}$cells, and the siRNA knockdown of p21 increased HIV-2 infection in hMDMs. These results agrees with the findings by Bergamaschi et al and Allouch et al that p21 restricted HIV-2 and SIV infection [16, 17]. Since Vpx proteins in HIV-2 and SIV are able to target SAMHD1 for proteasomal degradation $[30,45,46]$, the p21 dependent block of HIV-2 in hMDMs suggested a mechanism of host restriction that is less dependent on the level of cellular dNTPs.

\section{Conclusions}

HIV infection in macrophages is highly relevant to AIDS pathogenesis. Human macrophages have been described as a durable reservoir of HIV-1 characterized by the persistence of viral replication and the poor susceptibility to antiviral therapy $[47,48]$. The transmission of HIV-1 from macrophages to $\mathrm{CD} 4+\mathrm{T}$ lymphocytes can be achieved by efficient cell-to-cell transmission even when there is inadequate amount of cell-free virus in environment [48]. Here we show for the first time that p53 and its downstream gene p21 were induced in hMDMs in the early stage of HIV infection, and the elevated p53 and p21 inhibited reverse transcription. The underlined mechanism obtained in this study will shed light on the understanding of HIV pathogenesis, and control and management of AIDS disease.

\begin{abstract}
Abbreviations
FBS: Fetal bovine serum; HIV-1: The human immunodeficiency virus type 1; HIV-2: The human immunodeficiency virus type 2; hMDMs: Human monocyte derived macrophages; LTR: long terminal repeat sequence; p21: the cyclin-dependent kinase inhibitor p21 $1^{\text {Waf1/Cip } 1} ;$ p53: Tumor protein p53; PI: Propidium iodide; PKR: Double-stranded RNA (dsRNA)-dependent protein kinase; RNR2: Ribonucleotide reductase subunit R2; RT: HIV-1 reverse transcription; RT: Reverse transcription; SAMHD1: SAM domain and HD domain-containing protein 1; VSV-G: Vesicular stomatitis virus G-protein
\end{abstract}

\section{Acknowledgements}

We thank Dr. Eric Yager at Albany College of Pharmacy and Health Sciences for the discussion of this work and the assistance with flow cytometry analysis. We also would like to thank Dr. Timothy LaRocca at Albany College of Pharmacy and Health Sciences for assistance in cell viability experiments.

\section{Funding}

This study was supported by the startup fund and the scholarship of discovery intramural research grant to Dr. Binshan Shi by Albany College of Pharmacy and Health Sciences.

\section{Availability of data and materials}

All data generated or analyzed during this study are included in this published article.

Authors' contributions

BS, HS, SD, MK and KM performed experiments. BS and HS completed the manuscript. HW and CD provided important guidance and advice in this study. All authors read and approved the final manuscript.

Ethics approval and consent to participate

Not applicable.

Consent for publication

Not applicable.

\section{Competing interests}

The authors declare that they have no competing interests.

\section{Publisher's Note}

Springer Nature remains neutral with regard to jurisdictional claims in published maps and institutional affiliations. 


\section{Author details}

'Department of Basic and Clinical Sciences, Albany College of Pharmacy and Health Sciences, 106 New Scotland Ave, Albany, NY 12208, USA. ${ }^{2}$ Rutgers Cancer Institute of New Jersey, Rutgers the State University of New Jersey, New Brunswick, NJ 08903, USA. ${ }^{3}$ Center for Immunology and Microbial Disease, Albany Medical College, Albany, New York, Albany, NY 12208, USA.

Received: 24 September 2017 Accepted: 7 March 2018

Published online: 27 March 2018

\section{References}

1. Genini D, Sheeter D, Rought S, Zaunders JJ, Susin SA, Kroemer G, et al. HIV induces lymphocyte apoptosis by a p53-initiated, mitochondrial-mediated mechanism. FASEB J. 2001;15:5-6. http://www.ncbi.nIm.nih.gov/entrez/ query.fcgi? $\mathrm{cmd}=$ Retrieve\&db=PubMed\&dopt=Citation\&list_uids=11099484

2. Imbeault M, Ouellet M, Tremblay MJ. Microarray study reveals that HIV-1 induces rapid type-l interferon-dependent p53 mRNA up-regulation in human primary CD4+ T cells. Retrovirology. 2009;6:5. http://www.ncbi.nlm. nih.gov/entrez/query.fcgi?cmd=Retrieve\&db=PubMed\&dopt=Citation\&list_ uids $=19146679$

3. Yoon C-H, Kim S-Y, Byeon SE, Jeong Y, Lee J, Kim KP, et al. p53-derived host restriction of HIV-1 replication by protein kinase R-mediated tat phosphorylation and inactivation. J Virol. 2015;89:4262-80.

4. Takaoka A, Hayakawa S, Yanai H, Stoiber D, Negishi H, Kikuchi H, et al. Integration of interferon-alpha/beta signalling to p53 responses in tumour suppression and antiviral defence. Nature. 2003;424:516-23. http://www. ncbi.nlm.nih.gov/entrez/query.fcgi?cmd=Retrieve\&db=PubMed\&dopt= Citation\&list_uids $=12872134$

5. Duan L, Ozaki I, Oakes JW, Taylor JP, Khalili K, Pomerantz RJ. The tumor suppressor protein p53 strongly alters human immunodeficiency virus type 1 replication. J Virol. 1994;68:4302-13.

6. Gualberto A, Baldwin AS. p53 and Sp1 interact and cooperate in the tumor necrosis factor-induced transcriptional activation of the HIV-1 long terminal repeat. J Biol Chem. 1995;270:19680-3.

7. Bargonetti J, Chicas A, White D, Prives C. p53 represses Sp1 DNA binding and HIV-LTR directed transcription. Cellular and molecular biology (Noisy-leGrand, France) 1997:43:935-949.

8. Li CJ, Wang C, Friedman DJ, Pardee AB. Reciprocal modulations between p53 and tat of human immunodeficiency virus type 1. Proc Natl Acad Sci U S A. 1995;92:5461-4. https://doi.org/10.2307/2367535.

9. Cooper A, Garcia M, Petrovas C, Yamamoto T, Koup RA, Nabel GJ. HIV-1 causes CD4 cell death through DNA-dependent protein kinase during viral integration. Nature. 2013;498:376-9. http://www.ncbi.nlm.nih.gov/entrez/ query.fcgi? cmd=Retrieve\&db=PubMed\&dopt=Citation\&list_uids $=23739328$

10. Perfettini J-L, Castedo M, Roumier T, Andreau K, Nardacci R, Piacentini M, et al. Mechanisms of apoptosis induction by the HIV-1 envelope. Cell Death Differ. 2005;12(Suppl 1):916-23.

11. Cummins NW, Badley AD. Mechanisms of HIV-associated lymphocyte apoptosis: 2010. Cell Death and Disease. 2010;1:e99. https://doi.org/10.1038/ cddis.2010.77.

12. Bell DJ, Dockrell DH. Apoptosis in HIV-1 infection. J Eur Acad Dermatol Venereol. 2003;17:178-83.

13. Bakhanashvili M, Novitsky E, Lilling G, Rahav G. P53 in cytoplasm may enhance the accuracy of DNA synthesis by human immunodeficiency virus type 1 reverse transcriptase. Oncogene. 2004;23:6890-9. https://doi.org/10. 1038/sj.onc.1207846.

14. Bakhanashvili M. p53 enhances the fidelity of DNA synthesis by human immunodeficiency virus type 1 reverse transcriptase. Oncogene. 2001;20:7635-44.

15. Zhang J, Scadden DT, Crumpacker CS. Primitive hematopoietic cells resist HIV-1 infection via p21Waf1/Cip1/Sdi1. J Clin Investig. 2007;117:473-81. https://doi.org/10.1172/JCI28971.

16. Bergamaschi A, David A, Le Rouzic E, Nisole S, Barré-Sinoussi F, Pancino G. The CDK inhibitor p21Cip1/WAF1 is induced by FcgammaR activation and restricts the replication of human immunodeficiency virus type 1 and related primate lentiviruses in human macrophages. J Virol. 2009;83:12253-65. https:/doi.org/10.1128/JVI.01395-09.

17. Allouch A, David A, Amie SM, Lahouassa H, Chartier L. Margottin-Goguet F, et al. p21-mediated RNR2 repression restricts HIV-1 replication in macrophages by inhibiting dNTP biosynthesis pathway. Proc Natl Acad Sci U S A. 2013;110:E3997-4006. http://www.ncbi.n/m.nih.gov/entrez/query. fcgi?cmd=Retrieve\&db=PubMed\&dopt=Citation\&list_uids=24082141
18. Leng J, Ho HP, Buzon MJ, Pereyra F, Walker BD, Yu XG, et al. A cell-intrinsic inhibitor of HIV-1 reverse transcription in CD4 + T cells from elite controllers. Cell Host and Microbe. 2014;15:717-28.

19. Vázquez N, Greenwell-Wild T, Marinos NJ, Swaim WD, Nares S, Ott DE, et al. Human immunodeficiency virus type 1-induced macrophage gene expression includes the p21 gene, a target for viral regulation. J Virol. 2005;79:4479-91. https://doi.org/10.1128/JVI.79.7.4479-4491.2005.

20. Pauls E, Ruiz A, Riveira-Munoz E, Permanyer M, Badia R, Clotet B, et al. p21 regulates the HIV-1 restriction factor SAMHD1. Proc Natl Acad Sci. 2014;111: E1322-4. https://doi.org/10.1073/pnas.1322059111.

21. Allouch A, David A, Amie SM, Lahouassa H, Chartier L, Margottin-Goguet F, et al. Reply to Pauls et al.: p21 is a master regulator of HIV replication in macrophages through dNTP synthesis block. Proc Natl Acad Sci U S A. 2014;111:E1325-6. https://doi.org/10.1073/pnas.1322699111.

22. Chen H, Li C, Huang J, Cung T, Seiss K, Beamon J, et al. CD4+ T cells from elite controllers resist HIV-1 infection by selective upregulation of p21. J Clin Invest. 121:1549-60. http://www.ncbi.nlm.nih.gov/entrez/query.fcgi?.cmd= Retrieve\&db=PubMed\&dopt=Citation\&list_uids=21403397

23. Zhang J, Scadden DT, Crumpacker CS. Primitive hematopoietic cells resist HIV-1 infection via p21 Waf1/Cip1/Sdi1. J Clin Investig. 2007;117: 473-81.

24. Chowdhury IH, Wang X-F, Landau NR, Robb ML, Polonis VR, Birx DL, et al. HIV-1 Vpr activates cell cycle inhibitor p21/Waf1/Cip1: a potential mechanism of G2/M cell cycle arrest. Virology. 2003;305:371-7. http://www. ncbi.nlm.nih.gov/pubmed/12573582.

25. Amini S, Saunders M, Kelley K, Khalili K, Sawaya BE. Interplay between HIV-1 Vpr and Sp1 modulates p21WAF1 gene expression in human astrocytes. J Biol Chem. 2004;279:46046-56.

26. Kinnetz M, Alghamdi F, Racz M, Hu W, Shi B. The impact of p53 on the early stage replication of retrovirus. Virol J. 2017;14:151. https://doi.org/10.1186/ s12985-017-0820-7.

27. Furuya AKM, Sharifi HJ, Jellinger RM, Cristofano P, Shi B, de Noronha CMC. Sulforaphane inhibits HIV infection of macrophages through Nrf2. PLOS Pathog. 2016;12:e1005581.

28. Shi B, Kitchen C, Weiser B, Mayers D, Foley B, Kemal K, et al. Evolution and recombination of genes encoding HIV-1 drug resistance and tropism during antiretroviral therapy. Virology. 2010;404:5-20.

29. Mbisa JL, Delviks-Frankenberry KA, Thomas JA, Gorelick RJ, Pathak VK, Realtime PCR. Analysis of HIV-1 replication post-entry events. Methods Mol Biol. 2009:485:55-72. https://doi.org/10.1007/978-1-59745-170-3_5.

30. Hrecka K, Hao C, Gierszewska M, Swanson SK, Kesik-Brodacka M, Srivastava S, et al. Vpx relieves inhibition of HIV-1 infection of macrophages mediated by the SAMHD1 protein. Nature. 2011;474:658-61.

31. Zack JA, Arrigo SJ, Weitsman SR, Go AS, Haislip A, Chen IS. HIV-1 entry into quiescent primary lymphocytes: molecular analysis reveals a labile, latent viral structure. Cell. 1990;61:213-22. http://www.ncbi.nlm.nih.gov/ entrez/query.fcgi?cmd=Retrieve\&db=PubMed\&dopt=Citation\&list_uids= 2331748

32. Kootstra NA, Schuitemaker H. Proliferation-dependent replication in primary macrophages of macrophage-tropic HIV type 1 variants. AIDS Res Hum Retrovir. 1998;14:339-45. http://www.ncbi.nlm.nih.gov/entrez/ query.fcgi?cmd=Retrieve\&db=PubMed\&dopt=Citation\&list_uids=9519895

33. Korin YD, Zack JA. Nonproductive human immunodeficiency virus type 1 infection in nucleoside-treated G0 lymphocytes. J Virol. 1999;73:6526-32.

34. Kootstra NA, Zwart BM, Schuitemaker H. Diminished human immunodeficiency virus type 1 reverse transcription and nuclear transport in primary macrophages arrested in early G(1) phase of the cell cycle. J Virol. 2000;74:1712-7. http:/www. ncbi.nlm.nih.gov/entrez/query.fcgi?cmd=Retrieve\&db=PubMed\&dopt= Citation\&list_uids $=10644341$

35. Vatakis DN, Kim S, Kim N, Chow SA, Zack JA. Human immunodeficiency virus integration efficiency and site selection in quiescent CD4+ T cells. J Virol. 2009;83:6222-33.

36. Korin $Y D$, Zack JA. Progression to the G1b phase of the cell cycle is required for completion of human immunodeficiency virus type 1 reverse transcription in T cells. J Virol. 1998;72:3161-8.

37. Mlcochova P, Sutherland KA, Watters SA, Bertoli C, de Bruin RA, Rehwinkel J, et al. A G1-like state allows HIV-1 to bypass SAMHD1 restriction in macrophages. EMBO J. 2017;36:604-16. https://doi.org/10.15252/embj.201696025.

38. Harper JW, Elledge SJ, Keyomarsi K, Dynlacht B, Tsai LH, Zhang P, et al. Inhibition of cyclin-dependent kinases by p21. Mol Biol Cell. 1995;6:387-400. http://www.ncbi.nlm.nih.gov/pubmed/7626805. Accessed 20 Sep 2017 
39. Shang L, Zhou H, Xia Y, Wang H, Gao G, Chen B, et al. Serum withdrawal up-regulates human SIRT1 gene expression in a p53-dependent manner. J Cell Mol Med. 2009;13:4176-84. https://doi.org/10.1111/j.1582-4934.2008.00468.x.

40. Shi Y, Felley-Bosco E, Marti TM, Orlowski K, Pruschy M, Stahel RA. Starvationinduced activation of ATM/Chk2/p53 signaling sensitizes cancer cells to cisplatin. BMC Cancer. 2012;12:571. https:/doi.org/10.1186/1471-2407-12-571.

41. Franzolin E, Pontarin G, Rampazzo C, Miazzi C, Ferraro P, Palumbo E, et al. The deoxynucleotide triphosphohydrolase SAMHD1 is a major regulator of DNA precursor pools in mammalian cells. Proc Natl Acad Sci. 2013;110: 14272-7. https://doi.org/10.1073/pnas.1312033110.

42. Chowdhury IH, Wang XF, Landau NR, Robb ML, Polonis VR, Birx DL, et al. HIV-1 Vpr activates cell cycle inhibitor p21/Waf1/Cip1: a potential mechanism of G2/M cell cycle arrest. Virology. 2003;305:371-7. doi:S0042682202917770 [pii]

43. Cui J, Tungaturthi PK, Ayyavoo V, Ghafouri M, Ariga H, Khalili K, et al. The role of Vpr in the regulation of HIV-1 gene expression. Cell Cycle. 2006;5:2626-38. https://doi.org/10.4161/cc.5.22.3442.

44. Sawaya BE, Khalilit K, Mercer WE, Denisova L, Amini S. Cooperative actions of HIV-1 Vpr and p53 modulate viral gene transcription. J Biol Chem. 1998;273:20052-7.

45. Sharifi HJ, Furuya AKM, Jellinger RM, Nekorchuk MD, de Noronha CMC. Cullin4A and Cullin $4 \mathrm{~B}$ are interchangeable for HIV Vpr and Vpx action through the CRL4 ubiquitin ligase complex. J Virol. 2014;88:6944-58. https:/doi.org/10. 1128/JVI.00241-14

46. Goldstone DC, Ennis-Adeniran V, Hedden JJ, Groom HC, Rice Gl, Christodoulou E, et al. HIV-1 restriction factor SAMHD1 is a deoxynucleoside triphosphate triphosphohydrolase. Nature. 480:379-82. http://www.ncbi.nlm.nih.gov/entrez/ query.fcgi?cmd=Retrieve\&db=PubMed\&dopt=Citation\&list_uids=22056990

47. Garbuglia AR, Zaccarelli M, Calcaterra S, Cappiello G, Marini R, Benedetto A. Dynamics of viral load in plasma and HIV DNA in lymphocytes during highly active antiretroviral therapy (HAART): high viral burden in macrophages after 1 year of treatment. J Chemother. 2001;13:188-94. https://doi.org/10. 1179/joc.2001.13.2.188.

48. Igarashi T, Brown CR, Endo Y, Buckler-White A, Plishka R, Bischofberger N, et al. Macrophage are the principal reservoir and sustain high virus loads in rhesus macaques after the depletion of CD4+ T cells by a highly pathogenic simian immunodeficiency virus/HIV type 1 chimera (SHIV): implications for HIV-1 infections of humans. Proc Natl Acad Sci. 2001;98:658-63. https://doi.org/ 10.1073/pnas.021551798

\section{Submit your next manuscript to BioMed Central and we will help you at every step:}

- We accept pre-submission inquiries

- Our selector tool helps you to find the most relevant journal

- We provide round the clock customer support

- Convenient online submission

- Thorough peer review

- Inclusion in PubMed and all major indexing services

- Maximum visibility for your research

Submit your manuscript at www.biomedcentral.com/submit

) Biomed Central 